\title{
Central West Antarctica among the most rapidly warming regions on Earth
}

\author{
David H. Bromwich ${ }^{1 \star \dagger}$, Julien P. Nicolas ${ }^{1 \dagger}$, Andrew J. Monaghan ${ }^{2}$, Matthew A. Lazzara ${ }^{3}$, \\ Linda M. Keller ${ }^{4}$, George A. Weidner ${ }^{4}$ and Aaron B. Wilson ${ }^{1}$
}

\begin{abstract}
There is clear evidence that the West Antarctic Ice Sheet is contributing to sea-level rise. In contrast, West Antarctic temperature changes in recent decades remain uncertain. West Antarctica has probably warmed since the 1950s, but there is disagreement regarding the magnitude, seasonality and spatial extent of this warming. This is primarily because long-term near-surface temperature observations are restricted to Byrd Station in central West Antarctica, a data set with substantial gaps. Here, we present a complete temperature record for Byrd Station, in which observations have been corrected, and gaps have been filled using global reanalysis data and spatial interpolation. The record reveals a linear increase in annual temperature between 1958 and 2010 by $2.4 \pm 1.2{ }^{\circ} \mathrm{C}$, establishing central West Antarctica as one of the fastest-warming regions globally. We confirm previous reports of West Antarctic warming, in annual average and in austral spring and winter, but find substantially larger temperature increases. In contrast to previous studies, we report statistically significant warming during austral summer, particularly in December-January, the peak of the melting season. A continued rise in summer temperatures could lead to more frequent and extensive episodes of surface melting of the West Antarctic Ice Sheet. These results argue for a robust long-term meteorological observation network in the region.
\end{abstract}

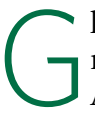
lacier acceleration along the Amundsen Sea coast ${ }^{1}$ has been responsible for the increasing mass loss from the West Antarctic Ice Sheet (WAIS) in recent years ${ }^{2}$. This has raised concerns about the present and future state of the WAIS, given its known potential instability in a warmer climate ${ }^{3}$. Key mechanisms behind this acceleration have been identified as the melting and thinning of the floating ice shelves triggered by warm ocean water ${ }^{4,5}$. In comparison, it is still a matter of debate whether the atmosphere above the WAIS has warmed over the past few decades, especially since the 1957-1958 International Geophysical Year, the start of the instrumental period in Antarctica ${ }^{6-8}$. Unlike Greenland, where the extent of surface melting has grown markedly ${ }^{9}$, West Antarctica has not shown any unequivocal signs of atmospheric warming ${ }^{10,11}$. The question is, therefore, whether West Antarctic temperatures have, indeed, not significantly changed (or even decreased) since the 1950s; or whether they have increased but not so much as to reach the melting point at the surface. In other words, could the WAIS be on the verge of becoming like Greenland? If so, is the exceptionally warm summer month of January 2005, when widespread surface melting occurred over a large portion of the WAIS (ref. 12; Supplementary Fig. S1), an early manifestation of this transition?

Assessing Antarctic climate change on timescales of a few decades is a well-recognized challenge owing to the paucity of surface observations. Accordingly, statistical methods have been used to reconstruct Antarctic near-surface temperatures by interpolating the sparse meteorological records available since the International Geophysical Year $6,7,13,14$. These reconstructions have produced contrasting, and sometimes contradictory, temperature trends over West Antarctica. This is not surprising as, in this region, the reconstructions can rely only on incomplete observations from a single site: Byrd Station $\left(80^{\circ} \mathrm{S}, 120^{\circ} \mathrm{W}\right.$; Fig. 1). Furthermore, West Antarctica is climatologically distinct from the rest of the continent, especially with greater influence from the tropics ${ }^{15-17}$, so that its climate variability and trends are not necessarily well reflected in peripheral temperature records.

Here, we present a new reconstruction of the Byrd temperature record that aims to improve on previous infilling methods ${ }^{14,18-20}$. The observations from the initial year-round occupied station (1957-1975) are combined with updated and corrected data from the automatic weather station (AWS) maintained since 1980 by the US Antarctic AWS Program ${ }^{21}$. Missing observations are estimated using adjusted temperature data from the ERA-Interim reanalysis ${ }^{22}$ for 1979-2012 and, before 1979, a combination of global reanalysis data and spatially interpolated observations from other Antarctic sites. Full details on the corrections to the observations and the infilling technique are provided in the Methods and Supplementary Methods. Although a full spatial interpolation of West Antarctic temperatures lies beyond the scope of this paper, the Byrd record is expected to provide insight into temperature changes over a large portion of the WAIS owing to its broad spatial footprint (Fig. 1).

\section{Improved temperature estimates}

The reliability of the temperature observations is a central premise of our reconstruction. The temperature readings were collected by professional weather observers until the 1970s, providing a robust anchor for the early portion of record. The operation of the AWS has proved more challenging in the harsh Antarctic environment, but the origins of the data gaps are well understood ${ }^{21}$.

\footnotetext{
${ }^{1}$ Polar Meteorology Group, Byrd Polar Research Center, and Atmospheric Sciences Program, Department of Geography, The Ohio State University, Columbus, Ohio 43210, USA, ${ }^{2}$ National Center for Atmospheric Research, Boulder, Colorado 80307, USA, ${ }^{3}$ Antarctic Meteorological Research Center, Space Science and Engineering Center, University of Wisconsin-Madison, Madison, Wisconsin 53706, USA, ${ }^{4}$ Department of Atmospheric and Oceanic Sciences, University of Wisconsin-Madison, Madison, Wisconsin 53706, USA. ${ }^{\dagger}$ These authors contributed equally to this work. *e-mail: bromwich.1@osu.edu.
} 


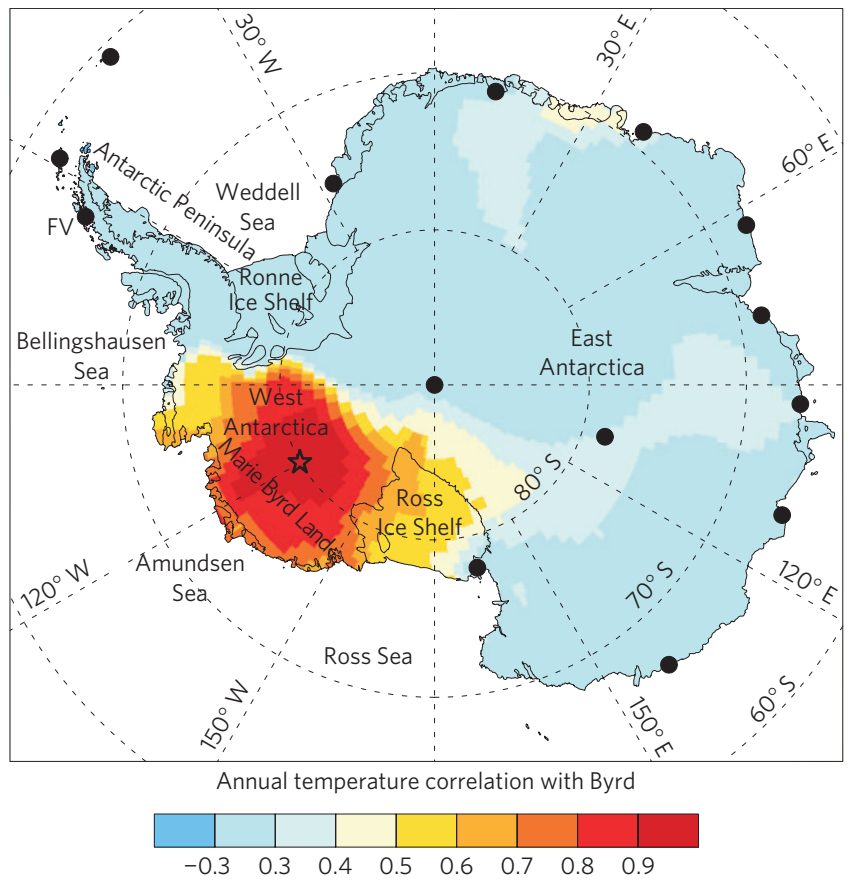

Figure 1 | Map of Antarctica and annual spatial footprint of the Byrd temperature record. The colour shadings show the correlation between the annual mean temperatures at Byrd and the annual mean temperatures at every other grid point in Antarctica. The correlations are computed using ERA-Interim 2-metre temperature time series from 1979 to 2011. The star symbol denotes the location of Byrd Station/AWS. The filled black circles denote the locations of permanent research stations with long-term temperature records (FV, Faraday/Vernadsky).

A reassessment of the calibration requirements of the AWS hardware was conducted in 2011 and led to the release of a corrected set of temperature observations in December 2011 (see Supplementary Methods).

Global atmospheric reanalyses are, in principle, uniquely suited for our reconstruction. By synthesizing a wide range of historical observations with the fields from a state-of-the-art atmospheric model, these reanalyses provide a best possible representation of the state of the atmosphere, complete both in space and time. Yet, the quality of their temperature estimates has long remained inadequate in Antarctica ${ }^{19,23,24}$, prompting the use of alternative reconstruction methods ${ }^{14,18-20}$. Compared with other reanalyses, ERA-Interim predicts the near-surface temperature at Byrd with markedly greater skill—even without the constraint of Byrd AWS observations-and could therefore be used for the infilling (see Methods and Supplementary Figs S8 and S9). The uncertainties of the reconstruction are larger during 1970-1978 owing to the lower reliability of the reanalysis data sets available for this period and the almost complete absence of Byrd observations. This limited portion of the record is found to have little impact on the long-term temperature trends (Supplementary Table S1).

\section{Temperature trends at Byrd Station}

The reconstructed Byrd record is presented in Fig. 2 as annual and seasonal mean temperature time series from 1957 to 2011. For the annual mean temperature, the linear trend calculated for $1958-2010$ reveals an average warming of $0.47 \pm 0.23^{\circ} \mathrm{C}$ per decade, statistically significant at the $99 \%$ confidence level (CL; Fig. 3a), which translates into a temperature increase of $2.44 \pm 1.19^{\circ} \mathrm{C}$ in 52 years. This warming is close to that measured at Faraday/Vernadsky, on the western coast of the Antarctic Peninsula $\left(0.58 \pm 0.31^{\circ} \mathrm{C}\right.$ per decade), a site already known for its rapid atmospheric warming ${ }^{25}$.
The temperature trends at Byrd and Faraday are substantially greater than the global average $\left(0.13 \pm 0.03{ }^{\circ} \mathrm{C}\right.$ per decade; ref. 26) and comparable in magnitude to the warming observed over land in the Northern Hemisphere high latitudes (Fig. 3c).

Seasonally, warming has occurred at Byrd throughout the year, yet without statistical significance in austral autumn (March, April, May (MAM); Fig. 3a). Spring (September, October, November $(\mathrm{SON}))$ exhibits the largest temperature trend $\left(0.82 \pm 0.40^{\circ} \mathrm{C}\right.$ per decade) and highest significance level (99\%). The trends in winter (June, July, August (JJA)) and summer (December, January, February (DJF)) are both statistically significant at the 95\% CL with $0.54 \pm 0.51{ }^{\circ} \mathrm{C}$ per decade and $0.30 \pm 0.27^{\circ} \mathrm{C}$ per decade, respectively. Importantly, the summertime warming is maximum and most significant $(\mathrm{CL}>99 \%)$ in December-January, the two climatologically warmest months of the year at Byrd and the peak of the melting season in Antarctica.

Signs of interdecadal variability are also evident in Byrd temperatures. On the annual scale, most of the warming at Byrd seems to have occurred during the mid- to late 1980s, with temperatures apparently levelling off since the early $1990 \mathrm{~s}$ (Fig. 2a). Both as a result of slower temperature increases and large interannual variability (particularly marked in SON in the latter part of the record), none of the trends attains statistical significance during 1980-2010, except for December-January (Fig. 3b).

\section{Comparison with other temperature reconstructions}

The temperature trends estimated from our Byrd record are contrasted with those derived from four sets of Antarctic temperature reconstructions $\mathrm{s}^{6,7,13,14}$ for 1958-2005 (Fig. 4) and 1958-2001 (Supplementary Table S2). Our record shows (almost systematically) stronger warming than all other data sets, although, because of the error bars, the various trend estimates are not always statistically distinguishable from one another.

There is overall agreement among the reconstructions on greatest seasonal warming occurring in $\mathrm{SON}$ (statistically significant only in our record and refs 6,14), which corroborates the conclusions from a recent investigation of the West Antarctic warming during this season ${ }^{8}$. However, our results and ref. 14 indicate temperature trends at least twice as large as the other reconstructions. The same two data sets also stand out in DJF with greater and statistically significant positive trends (marginally significant in ref. 14). This summer warming is notably at odds with the marked tropospheric cooling seen in Microwave Sounding Unit observations available since 1979 (ref. 27). In MAM and JJA, our reconstructed record agrees relatively well with ref. 6 for the 1958-2005 period. Both find JJA the second-fastest-warming season (yet without statistical significance), which confirms other evidence of surface and tropospheric winter warming over West Antarctica $^{17,27,28}$; and both show very similar temperature trends in MAM (significant only in ref. 6). In these two seasons (MAM and JJA), the other reconstructions ${ }^{7,13,14}$ have substantially smaller trends (or even negative values in ref. 7).

Annually, a pronounced warming in West Antarctica in recent decades has also been detected in recent borehole temperature measurements ${ }^{29,30}$, especially at the WAIS Divide drilling site, $160 \mathrm{~km}$ northeast of Byrd. The WAIS Divide record ${ }^{30}$, in particular, suggests a warming occurring later than at Byrd (early to mid-1990s) and continuing into the 2000s, instead of flattening out. Although this may reveal greater spatial heterogeneity in the temperature changes than inferred from the Byrd temperature footprint (Fig. 1), the discrepancy may also be related to the nonlinear temporal smoothing inherent to borehole temperature retrievals.

\section{Investigation of the winter and spring warming}

The causes of the West Antarctic warming in JJA and SON have been investigated in two recent studies ${ }^{8,17}$ that have highlighted, 


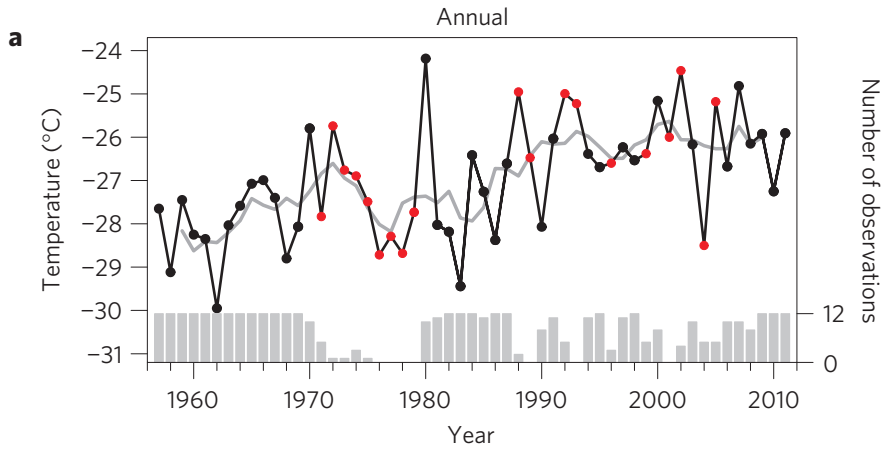

b

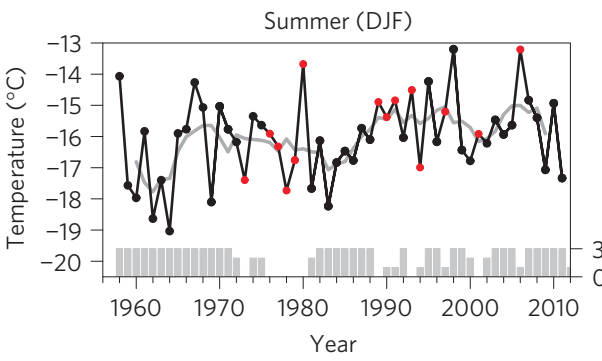

d

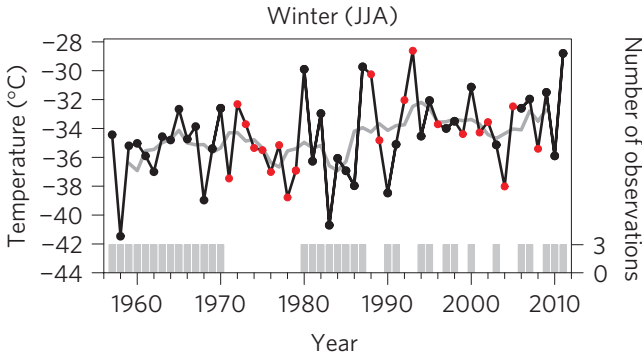

c

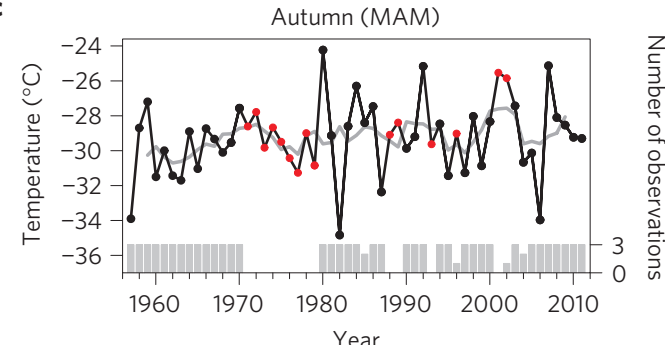

e

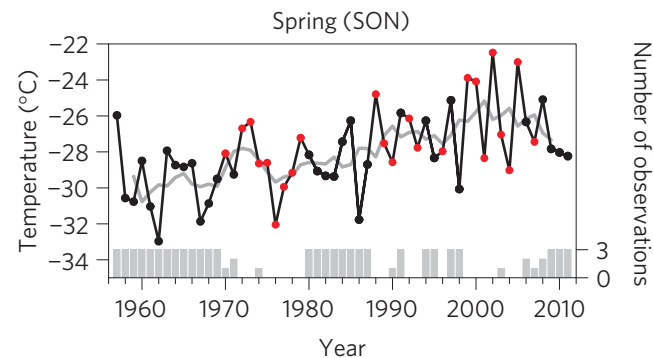

Figure 2 | Temperature time series from the reconstructed Byrd record. a-e, Annual (a) and seasonal (b-e) mean temperature time series. Red markers denote the portions of the record for which $>1 / 3$ of the observations are missing; black markers are used otherwise. The solid grey line represents the centred 5-year moving average temperature. The histograms (right vertical axis) show the number of monthly mean temperature observations available per year or per season. For summer (DJF), the year refers to January.

in particular, its linkage to lower-latitude sea surface temperature (SST) changes. Is the temperature variability observed at Byrd consistent with these findings? And can they also explain the warming in austral summer?

In JJA, the warming has been associated with an increase in geopotential heights over West Antarctica ${ }^{17}$ (Fig. 5a). This pattern has promoted onshore winds (warm advection) to Marie Byrd Land and is consistent with the spatial correlations between Byrd temperature and the $500 \mathrm{hPa}$ geopotential height (Z500) field during 1979-2009 (Fig. 5d). The absence of statistically significant trends in Z500 over the area can be explained by relatively little change since the early 1990s (Fig. 5g). The higher geopotential heights observed over West Antarctica have been described as being part of an atmospheric Rossby wave train forced by higher SST in the central tropical Pacific ${ }^{17}$. The signature of this wave train is clearly apparent in the correlations with Byrd temperature (Fig. 5d), more in JJA than in any other season. This atmospheric teleconnection is manifested in the second mode of covariability between tropical SST $\left(20^{\circ} \mathrm{S}-20^{\circ} \mathrm{N}\right)$ and Southern Hemisphere atmospheric circulation ${ }^{17}$. Notably, it involves an SST forcing distinct from the traditional eastern equatorial Pacific El Niño/Southern Oscillation (ENSO) region $^{17}$, yet consistent with the increasing frequency of El Niño events with SST anomalies in the central Pacific ${ }^{31}$.

In SON and DJF, the trends in Z500 project more poorly onto the spatial correlations than in JJA (Fig. 5b,e), suggesting a more complex causality of the warming. In other words, the mechanisms accounting for the secular temperature trends may differ (in part) from those responsible for the interannual temperature variability. In SON, the West Antarctic warming has been primarily attributed to lower geopotential heights in the South Pacific that have enhanced northerly warm air advection towards West Antarctica ${ }^{8}$ (Fig. 5b). This change in the atmospheric circulation is congruent with the trends in the two modes of high-latitude atmospheric variability often associated with ENSO, and known as the Pacific South American modes ${ }^{8,32}$. These trends, however, have been linked to positive SST anomalies in the tropical branch of the South Pacific Convergence Zone ${ }^{17}$ (SPCZ) and seem to be more clearly distinct from ENSO variability (either of the eastern or central Pacific type) compared with JJA (ref. 17). The close parallel between SST anomalies in the subtropical SPCZ region and West Antarctic temperatures over the past 50 years ${ }^{8}$ suggests a more southern location of the relevant SST forcing than indicated in ref. 17. We confirmed this hypothesis with a covariance analysis between SST and $200 \mathrm{hPa}$ geopotential heights (Z200) similar to that conducted in ref. 17, but encompassing SSTs beyond the tropical latitudes (see Supplementary Discussion and Figs S2 and S3).

The link between West Antarctic warming and (sub)tropical SST anomalies has not been established convincingly with model sensitivity experiments in SON (refs 8,17), in contrast to JJA (ref. 17), suggesting again that other mechanisms may be at play. Remarkably, the record-high temperatures at Byrd in the mid1990 s to late 2000s occurred along with a marked increase in the interannual temperature variability, which is also well reflected in the Z500 time series over the Bellingshausen Sea sector (Fig. 5h). 


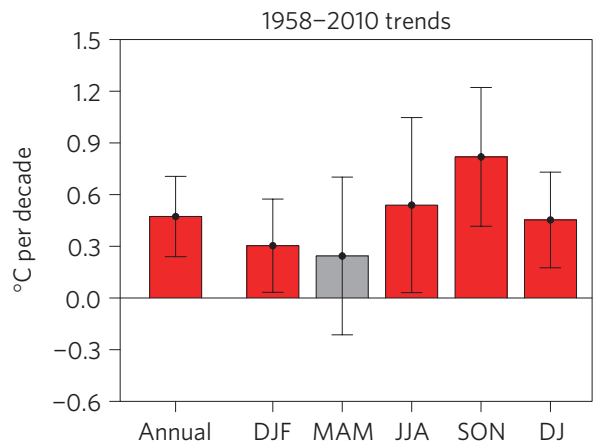

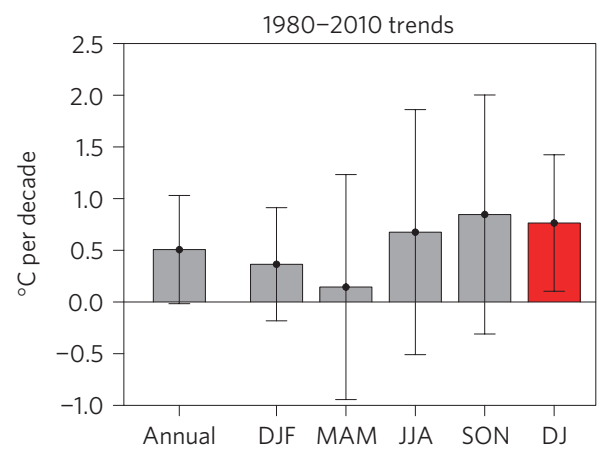

C

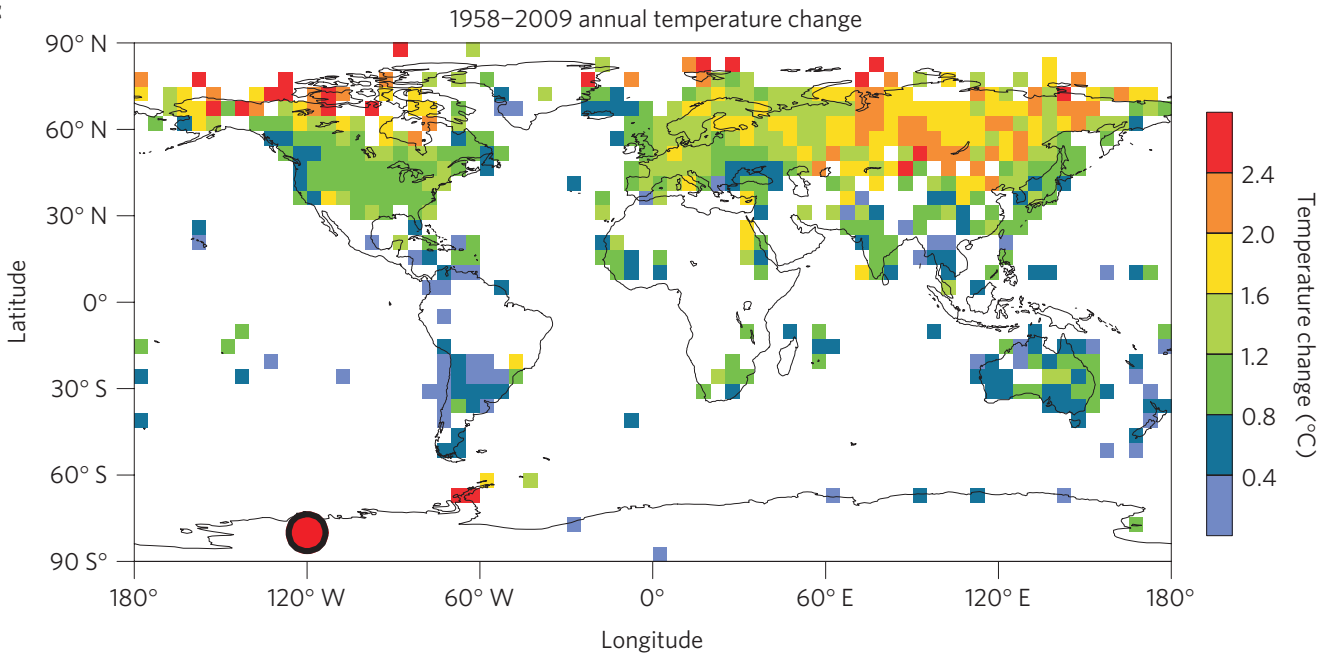

Figure 3 | Linear temperature trends at Byrd. a,b, Linear trends in the annual and seasonal mean temperature at Byrd during $1958-2010$ (a) and 1980-2010 (b). DJ denotes the December-January average. The error bars denote the 95\% confidence interval. Trends significant above (below) the 95\% level are shown in red (grey). Details on the error calculation are given in the Methods. The trend values and their statistical significance are given in Supplementary Table S1. c, Annual mean surface temperature change (that is, trend × number of years) during 1958-2009 from our Byrd record (red and black circle) and from the CRUTEM4 data set ${ }^{50}$ (background map).

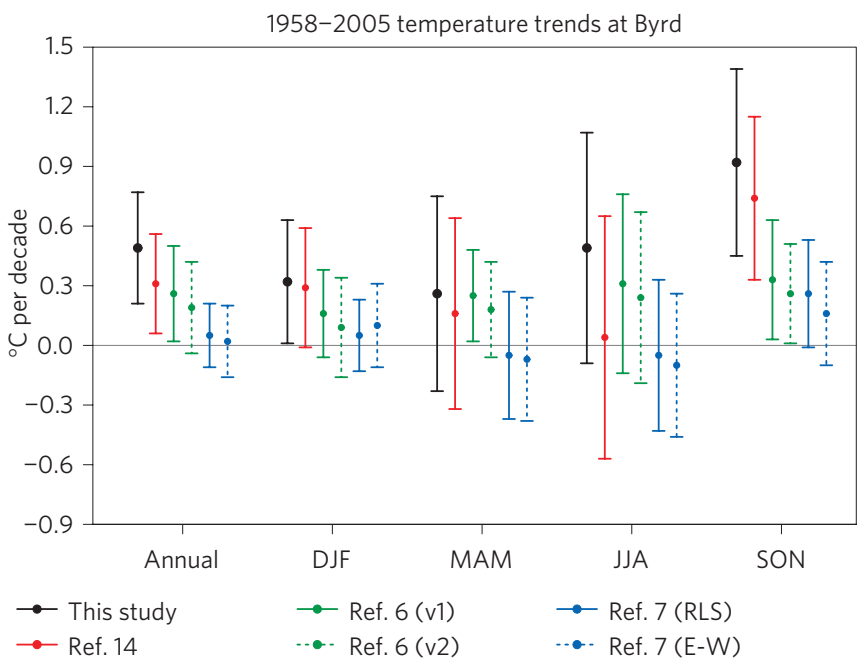

Figure 4 | Comparison of the temperature trends at Byrd from several reconstructions. Linear temperature trends for 1958-2005 from our reconstructed Byrd record (this study) and from other Antarctic temperature data sets (refs 6,7,14). For ref. 14, we use the updated version of its reconstructed Byrd record ${ }^{20}$. Further details about the data sets are given in Supplementary Table S2, along with the trend values. The error bars denote the $95 \%$ confidence interval and are calculated as explained in the Methods.
This increased variability can be related to the greater in-phase behaviour between the Southern Annular Mode (SAM) and ENSO observed since the early 1990s (refs 33,34). It also explains the small Z500 trends over the Bellingshausen Sea region (Fig. 5b), by compensation of large anomalies of opposite signs. Importantly, the warmest SON at Byrd (in 2002) coincided with an exceptional and well-documented sudden stratospheric warming over Antarctica, following an early breakdown of the polar vorte ${ }^{35}$. There is, however, no evidence of such a phenomenon in other abnormally warm springs at Byrd (for example, 1999, 2000 and 2005). Thus, one can assume that this mechanism is probably not a significant driver of the long-term SON warming, which is further supported by the fact that the Antarctic polar vortex tended to break up later in the 1990s than in the 1960s (ref. 36).

\section{Hypotheses for the summer warming}

Owing to the relative novelty of a West Antarctic warming in DJF, little has been said about its possible attribution. On the contrary, studies have generally emphasized the cooling effect of recent atmospheric circulation changes for West Antarctica in austral summer ${ }^{37-39}$. Largely dominated by the positive trend in the SAM index ${ }^{40}$, these changes have been characterized by lower geopotential heights over the continent ${ }^{41}$ (Fig. 5c) and stronger circumpolar westerlies, reducing the meridional heat exchange. This negative relationship between the strength of the SAM and West Antarctic temperatures is apparent in the Byrd temperature-Z500 correlations calculated for 1989-2011 (Supplementary Fig. S4), but mostly vanishes when the period is extended back to 1979 (Fig. 5f). 
a

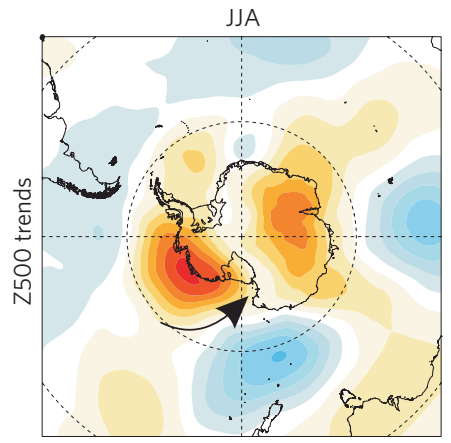

d

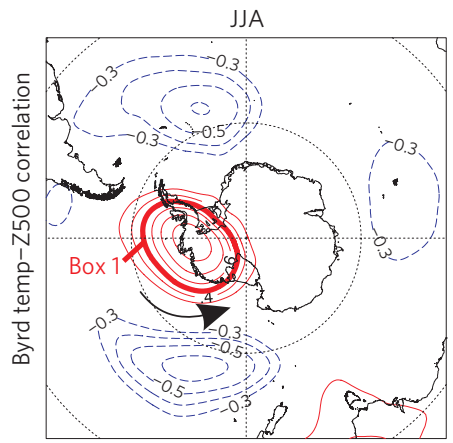

g

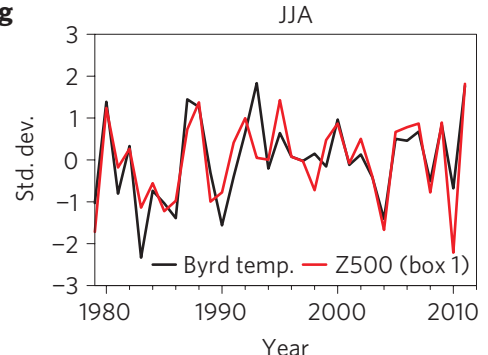

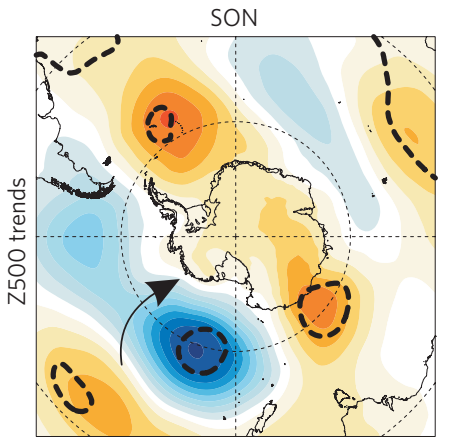

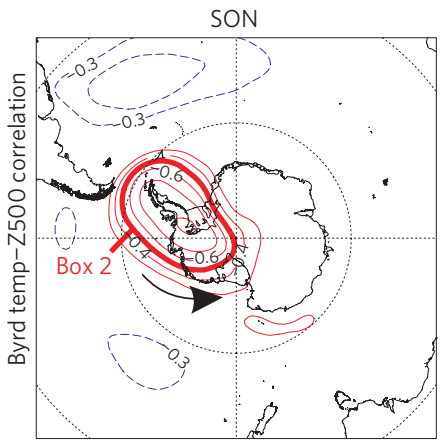

h

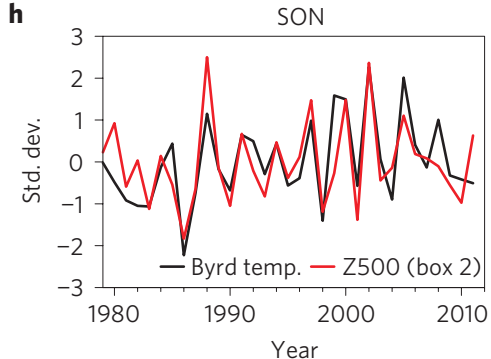

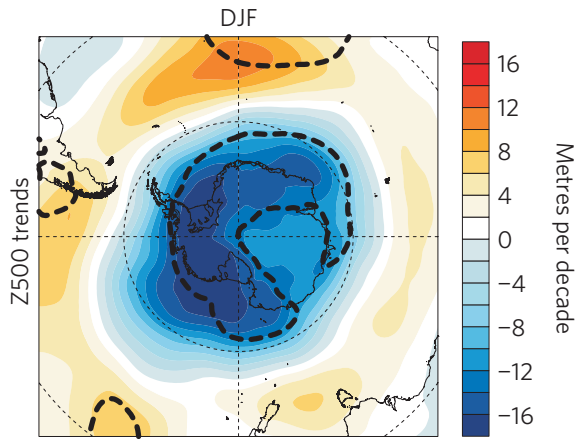

f

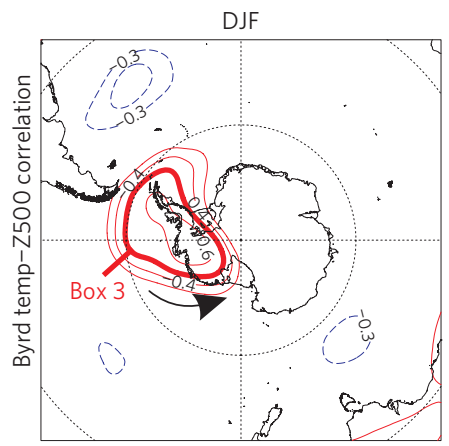

i

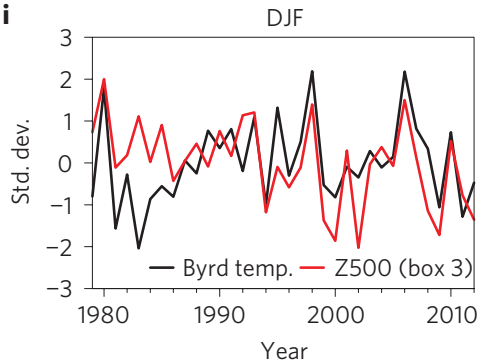

Figure 5 | Relationships between Byrd temperature and the atmospheric circulation during the three warming seasons. a-c, Linear trends in seasonal mean Z500 from ERA-Interim during 1979-2009. The thick black dashed lines denote the $95 \%$ significance level of the trends. d-f, Correlations ( $r$ )

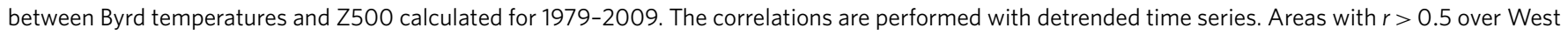
Antarctica are denoted with a thick red line. Solid thin red contours and dashed blue contours denote positive and negative correlations, respectively.

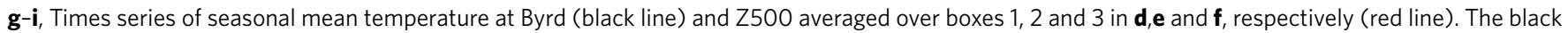
arrows in a-f show the direction of the prevailing warm air advection.

This supports the fact that the observed strengthening of SAM is inconsistent with a summer warming at Byrd. Moreover, it is clear from Fig. $5 \mathrm{i}$ that the changes in Z500 over the Bellingshausen Sea region during the 1980s fail to explain the quasi-stepwise increase in Byrd DJF temperature around 1986-1989.

We found this late 1980s warming to be consistent with a westward shift and deepening of the persistent centre of low pressure over the Amundsen/Ross Sea sector (see Supplementary Discussion and Figs S5 and S6). The resulting anomalous northerly warm advection towards Byrd was further enhanced by the adiabatic warming of air masses descending onto the lee side of Marie Byrd Land's coastal mountain ranges (föhn effect) ${ }^{42}$. However, the position of the low-known to be influenced by ENSO (ref. 43)—does not exhibit any significant trend over the post-1979 period $^{44}$ and, therefore, cannot account by itself for the long-term summer warming at Byrd. It is also noteworthy that the warming at Byrd coincided with a sharp decrease in summer sea-ice concentrations in the Bellingshausen Sea in 1989, which resulted from the permanent loss of multiyear sea ice ${ }^{45}$. There is, however, no clear evidence of a linkage between the two phenomena.

The SST region potentially linked to Byrd summer warming cannot be identified in a straightforward manner, as exemplified by the two strongly contrasting SST anomaly patterns associated with peaks in Byrd temperature in DJF 1997-1998 and DJF 20052006 (Fig. 2 and Supplementary Fig. S7). As in the other seasons, the second mode of covariability between (sub)tropical SST and Southern Hemisphere atmospheric circulation best captures the observed SST trends, in particular the warming of the subtropical SPCZ region ${ }^{46}$ (Supplementary Figs S2 and S3). This mode, which is separate from ENSO variability (as in SON), is thus likely to reflect the SST forcing responsible for long-term temperature trends at Byrd. The patterns of anomalies associated with this second mode show anomalous northerly winds over the Byrd region occurring in conjunction with higher SSTs over the subtropical SPCZ region (Supplementary Fig. S2). With this impact on the atmospheric circulation, the warming of the subtropical SPCZ region may have at least mitigated the cooling induced by a stronger SAM, and at most contributed to abnormally high temperatures at Byrd as seen in DJF 2005-2006 (Supplementary Fig. S7).

Our reconstructed Byrd temperature record reveals one of the most rapidly warming places on the planet since the 1950s, and its spatial footprint (Fig. 1) indicates that similar change has probably occurred over a broad area of West Antarctica. These results underscore the importance of maintaining a robust 
observational network in the region, first and foremost at Byrd (at present the area is devoid of upper-air observations). Our analysis confirms the strong seasonality in the characteristics of the warming previously found and suggests that not all causal mechanisms are yet fully identified or understood. The significant warming during austral summer reported here is a matter of concern because of its implications for the state of the WAIS and its coastal ice shelves. Despite no evidence of greater frequency or intensity of surface melting in this region ${ }^{10,11}$, the increase in the background summer temperature has, in effect, enhanced the probability of extensive melting events such as seen in January 2005 (ref. 12; Supplementary Fig. S1). Although Byrd (1,530 m a.s.l.) still has mean January temperatures around $-10^{\circ} \mathrm{C}$ (at most), one must bear in mind that the vast portion of West Antarctica lies at a lower elevation and is therefore more exposed to temperatures reaching $0^{\circ} \mathrm{C}$.

\section{Methods}

Near-surface temperature observations. Monthly mean temperature observations from Byrd Station (1957-1975), Byrd AWS (1980-2012) and other Antarctic research stations are obtained from the Antarctic READER archive ${ }^{47}$. For Byrd AWS, the original source of the observations is the Antarctic Meteorological Research Center (AMRC) at the University of Wisconsin-Madison, which provides three-hourly quality-controlled data to the READER (available at ftp://amrc.ssec.wisc.edu/pub/aws/antrdr/). For the AWS record, the READER monthly temperatures are used in our reconstruction provided that, for each month, $\geq 90 \%$ of the six-hourly data are available and no block of data is missing for more than two consecutive days (these criteria are reviewed in ref. 47).

Infilling of the Byrd record. For the period starting in January 1979, monthly 2-m temperature $\left(T_{2 \mathrm{~m}}\right)$ data from the ERA-Interim reanalysis ${ }^{22}$ (ERA-I) are used to fill in the gaps in the Byrd record. ERA-I assimilates observations from Byrd AWS for its surface analysis fields, but not for its surface forecast fields (see Supplementary Methods). Therefore, we use ERA-I forecast $T_{2 \mathrm{~m}}$ data for the infilling to avoid the problem of circularity between the predictor and the predicted variable. For months without any observations, ERA-I monthly $T_{2 \mathrm{~m}}$ is adjusted to the monthly mean temperature observations available before and after the months in question. This is done by estimating the reanalysis-versus-observations bias in a multiyear moving window (separately for each month of the year). The width of the window (5-9 years) depends on the number of observations available (a minimum of two observed monthly mean temperatures is required). This empirical adjustment technique accounts for the model-versus-observed elevation difference (or any other systematic bias), and prevents our reconstruction from being contaminated by spurious trends in ERA-I. A variant of the method is used when observations are partially available for a given month (see Supplementary Methods).

For 1970-1978, two methods were employed to estimate Byrd temperatures. In the first method, monthly mean temperature observations from Antarctic research stations with records going back to the 1950s (Fig. 1) were interpolated to the location of Byrd using a kriging method previously employed to reconstruct Antarctic temperatures ${ }^{14}$. In the second method, the monthly $T_{2 \mathrm{~m}}$ fields from the NCEP/NCAR (National Centers for Environmental Prediction/National Center for Atmospheric Research) Reanalysis ${ }^{48}$ (NNR) and the ERA-40 Reanalysis ${ }^{49}$ were used: NNR for the autumn-winter-spring months, and ERA-40 for the summer months, because of unrealistic temporal changes in the NNR temperatures in summer during the 1970s. The reanalyses' temperatures were adjusted to the observations (separately for each month) on the basis of the mean bias during 1957-1975. The final temperature values used in our reconstruction are taken as the average of the results from these two methods. The curves generated with the two methods are plotted separately in Supplementary Fig. S10.

Temperature trends and their uncertainties. To reduce the sensitivity of the results to anomalous temperatures near the start and end years, we consider the average of the trends computed between the first three years and last three years of each period analysed in Figs $3 \mathrm{a}, \mathrm{b}$ and 4 . The trend uncertainties quoted in the text (error bars in Figs 3a,b and 4) correspond to twice the total error and denote the $95 \%$ confidence interval, as determined by Student's $t$-test. The total error accounts for the standard error of the regression, calculated using a sample size corrected for autocorrelations in the time series; and the uncertainties of the infilling methods, estimated using a Monte Carlo procedure. Further details are provided in the Supplementary Methods.

Data. The reconstructed Byrd temperature data set used in this paper is archived on the AMRC's RAMADDA Data Repository (http://go.wisc.edu/ewl8tt). A version is also available on the Polar Meteorology Group's website (http://polarmet. osu.edu/Byrd recon/).
Received 2 May 2012; accepted 15 November 2012; published online 23 December 2012

\section{References}

1. Rignot, E. Changes in West Antarctic ice stream dynamics observed with ALOS PALSAR data. Geophys. Res. Lett. 35, L12505 (2008).

2. King, M. A. et al. Lower satellite-gravimetry estimates of Antarctic sea-level contribution. Nature http://dx.doi.org/10.1038/nature11621 (2012).

3. Joughin, I. \& Alley, R. B. Stability of the West Antarctic ice sheet in a warming world. Nature Geosci. 4, 506-513 (2011).

4. Jacobs, S. S., Jenkins, A., Giulivi, C. F. \& Dutrieux, P. Stronger ocean circulation and increased melting under Pine Island Glacier ice shelf. Nature Geosci. 4, 519-523 (2011).

5. Pritchard, H. D. et al. Antarctic ice-sheet loss driven by basal melting of ice shelves. Nature 484, 502-505 (2012).

6. Steig, E. J. et al. Warming of the Antarctic ice-sheet surface since the 1957 International Geophysical Year. Nature 457, 459-462 (2009).

7. O'Donnell, R., Lewis, N., McIntyre, S. \& Condon, J. Improved methods for PCA-based reconstructions: Case study using the Steig et al. (2009) Antarctic temperature reconstruction. J. Clim. 24, 2099-2115 (2010).

8. Schneider, D., Deser, C. \& Okumura, Y. An assessment and interpretation of the observed warming of West Antarctica in the austral spring. Clim. Dynam. 38, 323-347 (2012)

9. Tedesco, M. et al. The role of albedo and accumulation in the 2010 melting record in Greenland. Environ. Res. Lett. 6, 014005 (2011).

10. Tedesco, M. \& Monaghan, A. J. An updated Antarctic melt record through 2009 and its linkages to high-latitude and tropical climate variability. Geophys. Res. Lett. 36, L18502 (2009).

11. Kuipers Munneke, P., Picard, G., van den Broeke, M. R., Lenaerts, J. T. M. \& van Meijgaard, E. Insignificant change in Antarctic snowmelt volume since 1979. Geophys. Res. Lett. 39, L01501 (2012).

12. Nghiem, S. V., Steffen, K., Neumann, G. \& Huff, R. in Dynamic Planet: Monitoring and Understanding a Dynamic Planet With Geodetic and Oceanographic Tools, IAG Symp., Cairns, Australia 22-26 Aug. 2005 (eds Tregoning, P. \& Rizos, C.) 31-38 (2005).

13. Chapman, W. L. \& Walsh, J. E. A synthesis of Antarctic temperatures. J. Clim. 20, 4096-4117 (2007).

14. Monaghan, A. J., Bromwich, D. H., Chapman, W. \& Comiso, J. C. Recent variability and trends of Antarctic near-surface temperature. J. Geophys. Res. 113, D04105 (2008).

15. Guo, Z., Bromwich, D. H. \& Hines, K. Modeled Antarctic precipitation. Part II: ENSO modulation over West Antarctica. J. Clim. 17, 448-465 (2004).

16. Bindschadler, R. The environment and evolution of the West Antarctic ice sheet: Setting the stage. Phil. Trans. R. Soc., Ser. A 364, 1583-1605 (2006).

17. Ding, Q., Steig, E. J., Battisti, D. S. \& Kuttel, M. Winter warming in West Antarctica caused by central tropical Pacific warming. Nature Geosci. 4, 398-403 (2011).

18. Shuman, C. A. \& Stearns, C. R. Decadal-length composite inland West Antarctic temperature records. J. Clim. 14, 1977-1988 (2001).

19. Reusch, D. B. \& Alley, R. B. A 15-year West Antarctic climatology from six automatic weather station temperature and pressure records. J. Geophys. Res. 109, D04103 (2004)

20. Küttel, M., Steig, E. J., Ding, Q., Monaghan, A. J. \& Battisti, D. S. Seasonal climate information preserved in West Antarctic ice core water isotopes: Relationships to temperature, large-scale circulation, and sea ice. Clim. Dynam. 39, 1841-1857 (2012).

21. Lazzara, M. A., Weidner, G. A., Keller, L. M., Thom, J. E. \& Cassano, J. J. Antarctic Automatic Weather Station Program: 30 years of polar observations. Bull. Am. Meteorol. Soc. 93, 1519-1537 (2012).

22. Dee, D. P. et al. The ERA-Interim reanalysis: Configuration and performance of the data assimilation system. Q. J. R. Meteorol. Soc. 137, 553-597 (2011).

23. Marshall, G. J. Trends in Antarctic geopotential height and temperature: A comparison between radiosonde and NCEP-NCAR reanalysis data. J. Clim. 15, 659-674 (2002)

24. Bromwich, D. H. \& Fogt, R. L. Strong trends in the skill of the ERA-40 and NCEP-NCAR reanalyses in the high and middle latitudes of the Southern Hemisphere, 1958-2001. J. Clim. 17, 4603-4619 (2004).

25. Vaughan, D. G. et al. Recent rapid regional climate warming on the Antarctic Peninsula. Climatic Change 60, 243-274 (2003).

26. Hansen, J., Ruedy, R., Sato, M. \& Lo, K. Global surface temperature change. Rev. Geophys. 48, RG4004 (2010).

27. Johanson, C. M. \& Fu, Q. Antarctic atmospheric temperature trend patterns from satellite observations. Geophys. Res. Lett. 34, L12703 (2007).

28. Turner, J., Lachlan-Cope, T. A., Colwell, S., Marshall, G. J. \& Connolley, W. M. Significant warming of the Antarctic winter troposphere. Science 311, 1914-1917 (2006)

29. Barrett, B. E., Nicholls, K. W., Murray, T., Smith, A. M. \& Vaughan, D. G. Rapid recent warming on Rutford Ice Stream, West Antarctica, from borehole thermometry. Geophys. Res. Lett. 36, L02708 (2009). 
30. Orsi, A. J., Cornuelle, B. D. \& Severinghaus, J. P. Little Ice Age cold interval in West Antarctica: Evidence from borehole temperature at the West Antarctic Ice Sheet (WAIS) Divide. Geophys. Res. Lett. 39, L09710 (2012).

31. Lee, T. \& McPhaden, M. J. Increasing intensity of El Niño in the central-equatorial Pacific. Geophys. Res. Lett. 37, L14603 (2010).

32. Mo, K. C. Relationships between low-frequency variability in the Southern Hemisphere and sea surface temperature anomalies. J. Clim. 13, 3599-3610 (2000).

33. Stammerjohn, S. E., Martinson, D. G., Smith, R. C., Yuan, X. \& Rind, D. Trends in Antarctic annual sea ice retreat and advance and their relation to El Niño-Southern Oscillation and Southern Annular Mode variability. J. Geophys. Res. 113, C03S90 (2008).

34. Fogt, R. L., Bromwich, D. H. \& Hines, K. M. Understanding the SAM influence on the South Pacific ENSO teleconnection. Clim. Dynam. 36, 1555-1576 (2011).

35. J. Atm. Sci. 62 (2005).

36. Haigh, J. D. \& Roscoe, H. K. The final warming date of the Antarctic polar vortex and influences on its interannual variability. J. Clim. 22, 5809-5819 (2009).

37. Kwok, R. \& Comiso, J. C. Spatial patterns of variability in Antarctic surface temperature: Connections to the Southern Hemisphere Annular Mode and the Southern Oscillation. Geophys. Res. Lett. 29, 1705 (2002).

38. Gillett, N. P. \& Thompson, D. W. J. Simulation of recent Southern Hemisphere climate change. Science 302, 273-275 (2003).

39. Van den Broeke, M. R. \& van Lipzig, N. P. M. Changes in Antarctic temperature, wind and precipitation in response to the Antarctic Oscillation. Ann. Glaciol. 39, 119-126 (2004).

40. Marshall, G. J. et al. Causes of exceptional atmospheric circulation changes in the Southern Hemisphere. Geophys. Res. Lett. 31, L14205 (2004).

41. Thompson, D. W. J. \& Solomon, S. Interpretation of recent Southern Hemisphere climate change. Science 296, 895-899 (2002).

42. Nicolas, J. P. \& Bromwich, D. H. Climate of West Antarctica and influence of marine air intrusions. J. Clim. 24, 49-67 (2011).

43. Bertler, N. A. N. et al. El Niño suppresses Antarctic warming. Geophys. Res. Lett 31, L15207 (2004).

44. Turner, J., Phillips, T., Hosking, J. S., Marshall, G. J. \& Orr, A. The Amundsen Sea low. Int. J. Climatol. http://dx.doi.org/10.1002/joc.3558 (2012).
45. Jacobs, S. S. \& Comiso, J. C. Climate variability in the Amundsen and Bellingshausen Seas. J. Clim. 10, 697-709 (1997).

46. Ding, Q., Steig, E. J., Battisti, D. S. \& Wallace, J. M. Influence of the tropics on the Southern Annular Mode. J. Clim. 25, 6330-6348 (2012).

47. Turner, J. et al. The SCAR READER project: Toward a high-quality database of mean Antarctic meteorological observations. J. Clim. 17, 2890-2898 (2004).

48. Kalnay, E. et al. The NCEP/NCAR 40-Year Reanalysis Project. Bull. Am. Meteorol. Soc. 77, 437-471 (1996).

49. Uppala, S. M. et al. The ERA-40 re-analysis. Q. J. R. Meteorol. Soc. 131, 2961-3012 (2005)

50. Jones, P. D. et al. Hemispheric and large-scale land-surface air temperature variations: An extensive revision and an update to 2010. J. Geophys. Res. 117, D05127 (2012).

\section{Acknowledgements}

This work was financially supported by the National Science Foundation (NSF) through grant ATM-0751291. The Antarctic Meteorological Research Center, provider of the AWS observations, is supported by the NSF Office of Polar Programs through gran ANT-0838834. We thank H. Brecher, R. Fogt, C. Genthon, T. Wilson and S-H. Wang for their insight/assistance at various stages of this work. We are also grateful to S. Colwell (British Antarctic Survey) for maintaining the READER database. This is contribution 1428 of the Byrd Polar Research Center.

\section{Author contributions}

D.H.B., J.P.N. and A.J.M. designed the research. D.H.B. and J.P.N. performed the temperature reconstruction and wrote the paper. D.H.B., J.P.N. and A.B.W. analysed the results. M.A.L., L.M.K. and G.A.W. tested the AWS hardware and provided corrected AWS data. All authors commented on the manuscript.

\section{Additional information}

Supplementary information is available in the online version of the paper. Reprints and permissions information is available online at www.nature.com/reprints. Correspondence and requests for materials should be addressed to D.H.B.

\section{Competing financial interests}

The authors declare no competing financial interests. 